\title{
How to use preconceptions? The Contact Strategy dismantled
}

\author{
Harm J. A. Biemans \\ University of Wageningen/University of Nijmegen, The Netherlands
}

P. Robert-Jan Simons

University of Nijmegen, The Netherlands

The effects of the contact strategy (a computer-assisted instructional strategy aimed at conceptual change in text processing) were investigated by dismantling the strategy. An experiment with $86 \mathrm{Ss}$ (5th/6th-graders) was conducted in which the number of instructional steps was cumulatively varied from 0 steps (no activation) over I step (search for old idea) and 3 steps (1. search for old idea; 2. compare ard contrast with new information; 3. formulate new idea) to all 5 contact steps (1. search for old idea; 2. compare and contrast with new information; 3. formulate new idea; 4. apply new idea; 5. evaluate new idea). A design with 2 between-subjects factors (instructional strategy and students' familiarity with the central concepts from the 7 instructional texts used) and 2 within-subjects factors (type of learning performance test item and time of testing) was used. Dependent variables concerned quality of final conceptions and learning performance. Results indicated that the complete contact strategy was the most effective variant. It seemed to be the case, however, that students mainly focused their attention on the central concepts from the texts. In our view, instructional strategies to foster conceptual change should both support knowledge restructuring processes and offer a solution for this problem of selective attention.

\section{Introduction}

In the late sixties, Ausubel (1968) already stressed the relevance of prior knowledge for learning: in his view, the most important single factor influencing learning is what the learner already knows. Subsequently, many researchers have referred to the determining influence of prior knowledge on the learning process and on the learning results (see Weinert, 1989; Dochy, 1992). In many studies, 30 to 60 percent of the variance in learning results is explained by prior knowledge variables (Schmidt, 1984). Körkel (1987), who represented the relations between age, intelligence, metacognition, prior knowledge and performance in a Lisrel model, reported a parameter estimation of .93 for the structural relationship between prior knowledge and memory performance. 
Following Dochy (1988, p. 19), prior knowledge can be defined as "the learner's domain-specific prior knowledge state before studying a learning task". According to Alexander, Pate, Kulikowich, Farrell and Wright (1989) the terms "domain" or "domain-specific knowledge", "content-specific knowledge" and "subject-matter knowledge" all signify knowledge about a specific field of study (e.g., physical geography). The domain-specific prior knowledge state can serve as the base for future learning: if the learner has constructed representations of the content of a certain task domain (preconceptions) as a result of learning experiences in the past, he/she can use these preconceptions when he/she has to study related material. In this sense, learning should be considered as cumulative: the cumulative nature of learning is the most fundamental assumption concerning the learning process (Voss, 1987). Preconceptions can enable the learner to relate concepts, to think of examples, to structure learning material, etc. (Vermunt, 1992).

Unfortunately, the preconceptions students hold, are often incorrect or only partially correct. The existence of misconceptions is well documented in the literature on cognitive psychology, educational technology, science instruction, intelligent tutoring systems, mental models and other related fields (see Pfund \& Duit, 1991). As has been shown in many studies, these incorrect or partially correct conceptions tend to resist change: misconceptions and incomplete conceptions can block knowledge construction processes if they are not diagnosed and corrected (see Schmidt, 1988; Eylon \& Linn, 1988; Dochy, 1992). Even if the preconceptions of the learner are correct, a successful learning process is not guaranteed. Few students use their prior knowledge spontaneously and actively (Ali, 1990). Apparently, for many students, instructional strategies implemented in the learning environment are needed to support processes of prior knowledge activation and knowledge construction. These instructional strategies should be aimed at conceptual change: they should encourage students to bring their conceptions into conformity with the domain-specific knowledge from the learning task. Therefore, a learning environment for promoting conceptual change should evoke "cognitive accommodation" processes. "Cognitive accommodation" refers to a partial or radical change of the structures of existing conceptions (Nussbaum \& Novick, 1982). In this respect, "cognitive accommodation" differs from "cognitive assimilation". "Assimilation" can be described as integrating new information with preconceptions without changing the structure of these ideas (Salomon, 1989). Conceptual change, in other words, requires restructuring of knowledge.

Although there is some empirical evidence concerning the instructional factors that may contribute to knowledge restructuring (e.g., Pfund \& Duit, 1991), cognitive models and theories concerning knowledge acquisition under conditions of individual domain-specific misconceptions are still lacking. Following Glaser (1991), Tergan and Oestermeier (1993a, p. 1-2) concluded: "There is a need for research concerning the cognitive processes of knowledge restructuring as well as the instructional conditions that may foster processes of conceptual change (...) There is also a need for the development of powerful learning environments (...) to promote processes of conceptual change."

In this article, we would like to focus on the cognitive processes of knowledge restructuring and on the instructional conditions to promote these processes. Such instructional conditions could be characterised as "process-oriented": their aim is to ensure that students employ appropriate thinking activities in order to construct, change and use their conceptions of the learning content (Vermunt, 1992).

Strike and Posner (1985) proposed a theoretical framework with respect to conceptual change in which various instructional conditions to foster cognitive accommodation processes were discerned: students should feel dissatisfaction with their existing preconceptions, they should understand new scientific notions, in the first instance these notions should be plausible and they should allow students to solve problems.

In order to be able to restructure their knowledge, students first should become aware of their preconceptions: they should search for relevant preconceptions in their memory (Prawat, 1989). To help students to trace relevant prior knowledge, "exposing events" could be used. An exposing event can be described as "a phenomenon to evoke students' preconceptions in order to understand it" (Nussbaum \& Novick, 1982, p. 187). Next, students should compare 
and contrast their misconceptions with the information from the learning task (Hewson \& Hewson, 1984). With respect to these learning activities, Prawat (1989, p. 12-13) stated: "Students must first recognize that the new information is related to what they already know; they then have to link this information to two types of prior knowledge - that which is consistent with the scientific notions and that which is incompatible with those notions. It is the latter connection that leads to the realization that their own ideas are not complete or satisfying explanations and that the scientific view is a more convincing and powerful alternative." Awareness of inconsistencies, however, is not sufficient: cognitive accommodation also implies acceptance of the scientific notions (Siegler, 1983). An important condition for accepting a new conception is that students recognize its plausibility: they should experience that the new conception enables them to solve problems (and that their preconception does not). Therefore, they should have the opportunity to actually test and evaluate their new conception (Strike \& Posner, 1985).

Taking into account these cognitive and instructional conditions that had emerged from theoretical notions and empirical research, Ali (1990) created the so-called contact strategy (CONTinuousACTivation) to foster processes of conceptual change. (Whereas our research project is directly founded on Ali's conceptual framework and empirical findings, her work will be described in detail). This computer-assisted and process-oriented instructional strategy was typified by continuous activation of the conceptions of individual learners based on a heuristic model consisting of five steps aimed at conceptual change:

a) searching for own preconceptions (cf. Nussbaum \& Novick, 1982);

b) comparing and contrasting these preconceptions with the new information;

c) formulating new conceptions, based on the previous step (cf. Prawat, 1989);

d) applying the new conceptions;

e) evaluating the new conceptions, based on the previous step (cf. Strike \& Posner, 1985).

According to this activation model, students should be activated to make close connections between new information to be learned and existing prior knowledge and to correct their preconceptions if necessary.

The effects of the contact strategy on the conceptions and the learning results of the students (sixth-graders, primary education) were compared with the effects of the Before-After Strategy. In the case of the Before-After Strategy, the conceptions of the students were activated both before and after the presentation of the new textual information (previous research had shown that prior knowledge activation both before and after the presentation of the new information was more effective than activation either before or after the presentation of the text and more effective than no activation at all - see Ali, 1990). The contact strategy turned out to be more effective than the Before-After Strategy with respect to the final conceptions of the students and their scores on learning performance tests (as measured by means of the instruments that will be described in the section Design and materials). Although the contact strategy appeared to lead to conceptions of higher quality and to higher learning performance scores, Ali's study did raise several questions that were examined in our own study.

The first research question was to what extent the various steps of the contact strategy contributed to its effectiveness. Therefore, the contact strategy was dismantled in a systematic way. Subjects were assigned to four instructional conditions varying with respect to the number of steps of the particular instructional strategy:

1) step a - step e (contact);

2) step a - step c (new idea);

3) step a only (old idea);

4) none of the contact steps (no activation).

These four variants were used as experimental treatments for systematically testing the validity of the underlying theoretical assumptions (see Tergan \& Oestermeier, 1993b). In line with the preliminary conclusion that all activities from the activation model contributed to the effectiveness of the strategy (Ali, 1990, p. 143), we hypothesized that the complete contact strategy would be the most effective variant in terms of conceptions and learning results of the students: all instructional steps were assumed to contribute to the effectiveness of the strategy. 
The second research question concerned the effects of the degree of familiarity with the central concepts from the training texts. Tobias (1976) proposed that instruction affects new achievement as it interacts with learners' prior achievement or familiarity with the subject matter. Instructional treatment may differentially affect students, depending upon their level or type of prior knowledge. Ali (1990) reported that the contact strategy was especially effective for students who already were very familiar with the central concepts from the training texts. She assumed that these students held more conceptions (both correct conceptions and misconceptions) before studying the texts. This would make the contact strategy more suitable because these students could use their own preconceptions as starting-point for knowledge restructuring (changing conceptions). On the other hand, students who were not very familiar with the central concepts from the texts, were not supposed to hold many (mis)conceptions in advance because of a lack of former learning experiences. Ali assumed that these students were mainly involved in knowledge construction processes (aimed at constructing a conception). This assumption was tested in our study: the effects of the degree of familiarity were examined in relation to the specific instructional strategy. It was hypothesized that the complete contact strategy would be the most effective variant for "highly familiar" students. According to our expectations, students who are not very familiar with the concepts to be treated, would profit more from one of the dismantled variants (the new idea or the old idea strategy).

In addition, we assumed that the effects of the contact strategy would depend on the degree of resemblance between the "exposing events" (cf. Nussbaum \& Novick, 1982) that were used to activate the preconceptions of the students and the performance test questions. We presupposed that students who study texts guided by the contact strategy, would mainly focus on the relations between the central concepts from the texts (as represented by the "exposing events") and less on the other information from the learning tasks. This assumption was derived from the selective-attention hypothesis (Pichert \& Anderson, 1977; Anderson \& Pichert, 1978; Goetz, Schallert, Reynolds, \& Radin, 1983; Vonk, 1986). According to Machiels-Bongaerts (1993, p. 113), who tested the selective-attention hypothesis in - expository - text processing, “... activating prior knowledge results in a selection process during information processing. Only information corresponding with the knowledge activated would be processed in depth, resulting in better recall of that information".

In our view, the selective-attention hypothesis is in line with recent instructional theories stressing the importance of domain-specificity and "situatedness" of cognitions in knowledge acquisition (e.g., Brown, Collins, \& Duguid, 1989; Weinert \& Helmke, 1993). The effect of the factor "relatedness", however, was not examined in Ali's (1990) work (1990). Therefore, in our study, we decided to test the selective-attention hypothesis: we hypothesized that the complete contact strategy would lead to the highest learning performance scores on directly related test questions and to the lowest scores on questions that were not directly related to the activated knowledge (as opposed to the no activation condition).

Finally, we presupposed that the complete contact strategy would result in better maintenance of the acquired knowledge than the other three instructional conditions from the present study. We assumed that students who are supported by the contact strategy while studying texts, would construct more valid and integrated conceptions with more adequate retrieval paths (see Schmidt, 1982). In our view, these conceptions would serve as a solid base for retrieval in the longer term with better maintenance of the acquired knowledge as a result.

\section{Method}

\section{Subjects}

Subjects were 86 students, being 10 to 13 years old and attending three different combination classes of two primary schools ( $46 \mathrm{fifth}$ graders and 40 sixth graders). After being matched on the basis of their competence level as judged by their teacher and their grade, Ss were assigned to the four instructional conditions at random. 


\section{Design and materials}

A factorial design with two between-subjects factors called Instruction and Familiarity was used. Subjects were assigned to four instructional conditions varying with respect to the number of steps of the particular computer-assisted strategy. Subjects assigned to the first Instructional condition $(N=21)$ studied the training texts supported by the contact strategy as designed by Ali (1990). In the case of the second instructional condition (the new idea condition; $N=21$ ), the fourth and fifth contact step (see Introduction section) were not included in the instructional strategy. Subjects assigned to the third instructional condition (the old idea condition; $N=21$ ) only had to perform the first contact step ("searching for own preconceptions"). Finally, in the case of the fourth instructional condition, the no activation condition $(N=23)$, Ss only had to study the texts. Their preconceptions and final ideas were not activated.

Following Ali (1990), the second between-subjects factor Familiarity was based on the total score on the Familiarity rating scale filled in by the Ss before the introduction session. This Familiarity rating scale was a list of 18 central concepts from the training texts. With each word, Ss had to state on a 3-point scale how often they had heard, read or seen something about that particular concept before. Based on the total familiarity score, Ss were assigned to the High familiarity group $(N=42)$ or the Low familiarity group $(N=44)$ with the median as the criterion.

The effects of the between-subjects factors on the final conceptions of the students were measured by means of so-called idea questions. Except for Ss assigned to the condition no activation, Ss had to state their final conception at the end of each of the seven training sessions by answering the particular idea question $(N=63)$. An idea question could be described as a concrete problem involving the central concepts from the corresponding training text. Subjects had to choose from six answer alternatives that corresponded to different conceptions of the relations between the central concepts. One of these answer alternatives corresponded to the scientific notion as explained in the text. The answer was regarded as the final conception. A mean quality score for the final conceptions was calculated by dividing the sum score by the number of questions ( 7 items). In this case, an ANOVA with the two between-subjects factors Instruction and Familiarity and the mean quality score for the final conceptions as the dependent variable was carried out.

The effects of the between-subjects factors on the learning results were measured by means of posttests that were administered immediately after the corresponding training session (Ss had to study seven training texts with subsequent posttest questions) and by means of a retention test that was delivered two weeks after the last training session.

Each of the seven computer-based posttests consisted of 9 questions (63 items) with four answer alternatives. All questions were classified as "directly related to the idea question" ( 31 items) or as "not directly related" (32 items). The criterion for this classification was the degree of conceptual resemblance of the particular performance test question with the idea question of the corresponding training session. With the posttests data, an overall mean score for the related questions and an overall mean score for the non-related questions were calculated by dividing the sum score by the number of questions.

The cornputer-based retention test consisted of 42 questions that were selected from the seven posttests. Again, the questions were classified as "directly related to the idea question" (21 items) or as "not directly related" (21 items). With the retention test data, a mean score for the related questions and a mean score for the non-related questions were calculated by dividing the sum score by the number of questions.

In this case, a mixed between-within-subjects design was used (Tabachnik \& Fidell, 1983). The factor Relatedness with the levels Directly related and Not directly related was introduced as the first within-subjects factor and the factor Testing Time with the levels Posttests and Retention test was introduced as the second within-subjects factor. Thus, one full linear model covering two between-subjects factors (Instruction and Familiarity) and two within-subjects factors (Relatedness and Testing Time) was used (repeated measurement ANOVA).

After the training, Ss filled in the so-called Statement List "Studying a text" (SLS). This inventory consisted of three parts. With the first part of the SLS, a check-list, Ss had to identi- 
fy the learning activities that could be performed to construct a correct conception while studying a text. The activities that were scored as adequate, corresponded to the various contact steps. With the second part of the inventory, Ss had to state how often they had employed the corresponding learning activities during the training. Finally, with the third part of the SLS, Ss had to describe why it could be important to perform the various contact steps while studying a text and how these steps could be performed. The answers of the Ss were scored in terms of adequate or inadequate, depending on the degree of resemblance to the training heuristic. For each of the three parts of the SLS, a mean score was calculated by dividing the sum score by the number of items. The three mean scores were regarded as repeated measures: in this case, again, a mixed between-within-subjects design was used (between-subjects factors: Instruction and Familiarity; within-subjects factor SLS-scale). The SLS data were used to check the experimental manipulations.

\section{Procedure and training}

The experiment consisted of eleven sessions for each subject, two sessions a week. During the first session, Ss filled in the Familiarity rating scale (see section Design and materials) and during the second session the training procedure was explained and discussed with the Ss. With this introduction session, Ss were divided into subgroups, depending on the instructional condition they had been assigned to. Subjects also had to explore the particular instructional strategy on the computer in small groups. The structure of this introduction lesson was similar to the structure of the training lessons.

During the next seven sessions, Ss had to study the seven training texts individually, supported by the particular instructional strategy. Subjects assigned to the first instructional condition studied the training texts supported by the contact strategy (see also Ali, 1990).

The contact strategy was based on a heuristic model consisting of five steps aimed at conceptual change. The contact steps can be depicted as a flow chart (see Figure 1).

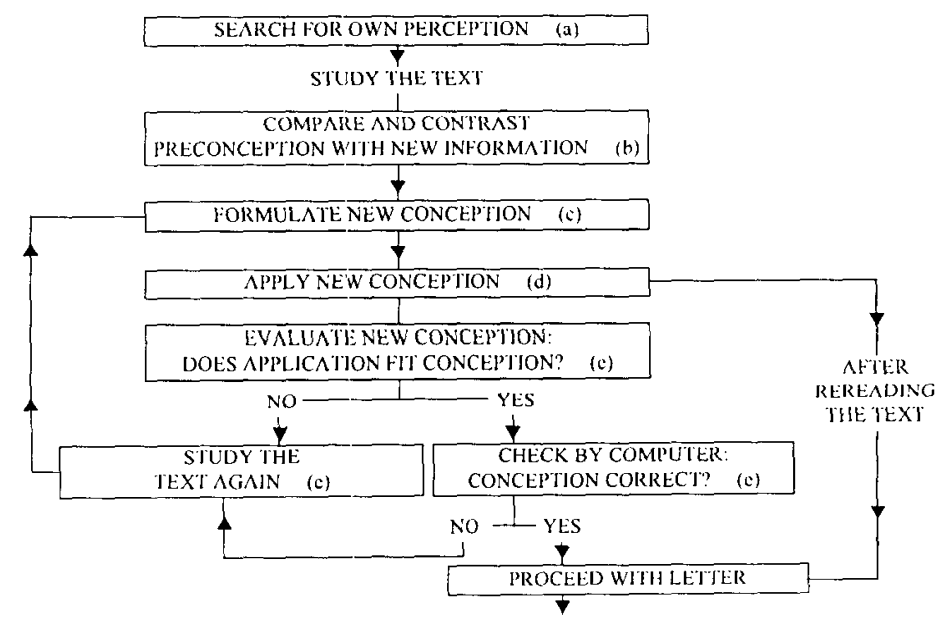

Figure 1. The steps of the contact strategy (Ali, 1990, p. 123)

At the beginning of each training session, Ss had to search for their preconception by answering the particular idea question (see section Design and materials). For example, the idea question of the seventh training session ran as follows:

When Columbus set sail in 1492, the wind did not blow him straight to the equator. Instead, he was blown to America with a curve to the right. Can you explain this? 
Subjects had to choose from six answer alternatives that corresponded to different conceptions of the relations between the central concepts from the training text. The answer was regarded as the criginal idea or preconception of the particular subject.

When Ss had answered the idea question, they had to study the new information from the first part of the text. The texts were all relatively short (7-8 text screens plus 2-3 pictures; 400-550 words). The training texts dealt with physical geography, treating concepts like equator, earth rotation, rain, wind, atmospheric pressure, etc. There were no time limits: each student could take the time he/she needed to study the text screens and to employ the learning activities corresponding with the steps of the instructional strategy. Inevitably, the amount of time students needed to finish the training sessions was dependent on the number of instructional steps: on the average, students from the contact condition needed more time than students from the no activation condition. At the end of the training, however, time differences had become less (see also Ali, 1990).

After studying the first part of the text, Ss had to compare and contrast their original idea with the essential information from the text. Subjects had to state whether their idea was in concordance with the new information or not. After this comparison, the idea question was presented again: Ss had to choose a new idea based on the previous step (if they thought that their original idea was correct, they were instructed to select the same answer alternative; if they thought that their idea was incorrect, however, they were told to pick another, better alternative).

The next step was "applying the new conception". Subjects had to answer a so-called practice question on the basis of their new idea. A practice question was always directly related to the corresponding idea question. In the case of a practice question, Ss had to choose from four answer alternatives. Finally, Ss had to evaluate their new conception by comparing their new idea with their answer to the practice question. Subjects had to state whether both answers were in concordance with one another or not. If they thought that the answers were not in concordance with one another, Ss had to study the most important part of the text again. They had to discover by themselves what mistakes they had made. After rereading the text, they had to formulate a new idea and apply this conception again. The same procedure had to be followed if the idea of the Ss was not correct. Therefore, their idea was checked by the computer.

The sequence of steps was always performed twice by the Ss during one training session. During the training sessions, additional information concerning the various steps of the strategy was presented in the form of so-called "How" and "Why" parts (cf. Biemans, 1989; De Jong \& Simors, 1990; Biemans \& Simons, 1992). The "How" parts contained information about how that particular step could be realized in terms of concrete activities and in the "Why" parts the relevance of the particular step was explained. The instructional steps were also visualized by means of cartoons.

At the end of each session, Ss had to state their final conception by answering the particular idea question. Their answer was regarded as their final idea or conception. Moreover, they had to make the corresponding posttest that was administered on the computer as well (see section Design and materials).

During the tenth session, Ss filled in the Statement List "Studying a text" (SLS). Finally, two weeks after the last training session, Ss made the retention test. The retention test was administered on the computer as well (see section Design and materials).

\section{Results}

To find out whether the training had an effect on the quality of the final conceptions, an ANOVA with the between-subjects factors Instruction and Familiarity and the mean quality score for the final conceptions as the dependent variable was carried out. Subjects assigned to the instructional condition no activation were not included in this analysis because their final ideas had not been activated: the factor Instruction only had three levels $(N=63)$. This analysis revealed a significant main effect of the factor Instruction $(F(2,57)=10.11, p<.001)^{1}$ : the quality of the final conceptions of the Ss from the condition old idea was lower than the quality of 
the final ideas of the Ss from the conditions contact $(t=-4.49, p<.001)$ and new idea $(t=-2.75$, $p<.01)$ while the difference between the conditions contact and new idea $(t=1.77, p=.08)$ was not significant (see Table 1).

\section{Table 1}

Mean scores, standard deviations and $N$ of Ss per cell for the three Instruction conditions with respect to the quality of the final conceptions

\begin{tabular}{lccc}
\hline Instruction conditions & $M$ & $S D$ & $N$ \\
\hline Contact & .65 & .22 & 21 \\
New idea & .48 & .25 & 21 \\
Old idea & .26 & .21 & 21 \\
\hline
\end{tabular}

No significant main effect of the factor Familiarity $(F(1,57)=1.83, p=.18)$ was found. The interaction effect between Instruction and Familiarity $(F(2,57)=4.51, p<.05)$, however, turned out to be significant: while no significant interaction effects with Familiarity were found between the conditions contact and old idea $(t=-.20, \mathrm{p}=84)$ and between the conditions new idea and old idea ( $t=2.37, p=.02)$, the interaction effect with Familiarity was significant between the conditions contact and new idea $(t=-2.77, p<.01)$. If Ss were not very familiar with the central concepts from the training texts, the quality of the final ideas of the Ss from the conditions contact and new idea was comparable. However, if Ss were very familiar with these concepts, the quality of the final ideas of the Ss from the contact condition was higher than the quality of the final ideas of the Ss from the new idea condition (see Table 2).

Table 2

Mean scores, standard deviations and $N$ of Ss per cell for the six Instruction X Familiarity groups with respect to the quality of the final conceptions

\begin{tabular}{|c|c|c|c|}
\hline Instruction conditions & \multirow[t]{2}{*}{$M$} & \multirow[t]{2}{*}{$S D$} & \multirow[t]{2}{*}{$N$} \\
\hline & & & \\
\hline Contact & .52 & .21 & 9 \\
\hline New idea & .59 & .19 & 7 \\
\hline \multirow[t]{2}{*}{ Old idea } & .21 & .20 & 16 \\
\hline & & & \\
\hline Contact & .74 & .18 & 12 \\
\hline New idea & .43 & .27 & 14 \\
\hline Old idea & .40 & .19 & 5 \\
\hline
\end{tabular}

To determine the training effects on the performance test scores, a repeated measurement ANOVA with two between-subjects factors (Instruction and Familiarity) and two within-subjects factors (Relatedness and Testing Time) was carried out. Because the data of 4 Ss were missing, this analysis was performed based on the data of $82 \mathrm{Ss}$.

The main effects of the factors Instruction $(F(3,74)=1.28, p=.29)$ and Familiarity 
$(F(1,74)=1.99, p=16)$ were not significant. The interaction effect between Instruction and Familiarity $(F(3,74)=1.20, p=.31)$ turned out not to be significant as well.

The analysis, however, revealed a significant interaction effect between Instruction and Relatedness $(F(3,74)=10.16, p<.001)$ : significant interaction effects with Relatedness were found between the conditions contact and no activation $(t=5.41, p<.001)$, new idea and no activation $(t=2.89, p<.005)$ and old idea and no activation $(t=3.27, p<.005)$. Especially in the case of questions that were not directly related to the idea question of the corresponding training session, differences were found between the various instructional conditions: with nonrelated questions, Ss from the condition no activation had higher scores than Ss from the other three conditions (see Table 3 ).

Table 3

Mean scores, standard deviations and $N$ of Ss per cell for the four Instruction conditions with performance test questions that were directly related to the particular idea question and with questions that were not directly related

\begin{tabular}{|c|c|c|c|}
\hline Instruction conditions & $M$ & $S D$ & $N$ \\
\hline \multicolumn{4}{|c|}{ Related questions } \\
\hline Contact & .53 & .15 & 19 \\
\hline New idea & .52 & .14 & 20 \\
\hline Old idea & .46 & .11 & 21 \\
\hline No activation & .51 & .19 & 22 \\
\hline \multicolumn{4}{|c|}{ Non-related questions } \\
\hline Contact & .42 & .14 & 19 \\
\hline New idea & .46 & .19 & 20 \\
\hline Old idea & .42 & .13 & 21 \\
\hline No activation & .56 & .20 & 22 \\
\hline
\end{tabular}

Moreover, the interaction effect between Instruction and Testing Time $(F(3,74)=5.99$, $p<.001)$ was significant: significant interaction effects with Testing Time were found between the conditions contact and new idea $(t=-2.52, p<.01)$, contact and old idea $(t=-2.97, p<.005)$ and contact and no activation $(t=-4.11, p<.001)$. For $S$ s from the contact condition, the learning performance scores on the posttests and on the retention test were comparable. For Ss from the other three instructional conditions, however, there was a decrease of the performance scores (see Table 4).

Finally, the interaction effect between the four factors Instruction, Familiarity, Relatedness and Testing Time $(F(3,74)=2.24, p<.10)$ turned out to be significant (see Table 5): a significant interaction effect was found between the conditions contact and no activation $(t=2.51, p<.01)$ (see Figure 2).

With questions that were directly related to the particular idea question, the following results were found: for students who were not very familiar with the concepts from the texts, the conditions contact and no activation led to comparable performance scores on the posttests while the contact strategy resulted in higher scores on the retention test; for "highly familiar" students, the no activation condition led to higher scores on the posttests while the contact strategy resulted in higher scores on the retention test (see Figure 2). 
Table 4

Mean scores, standard deviations and $N$ of Ss per cell for the foul Instruction conditions on the posttests and on the retention test

\begin{tabular}{|c|c|c|c|}
\hline Instruction conditions & \multirow[t]{2}{*}{$M$} & \multirow[t]{2}{*}{$S D$} & \multirow[t]{2}{*}{$N$} \\
\hline & & & \\
\hline Contact & .46 & .16 & 19 \\
\hline New idea & .52 & .18 & 20 \\
\hline Old idea & .46 & .14 & 21 \\
\hline \multirow[t]{2}{*}{ No activation } & .58 & .19 & 22 \\
\hline & & & \\
\hline Contact & .48 & .14 & 19 \\
\hline New idea & .46 & .16 & 20 \\
\hline Old idea & .42 & .11 & 21 \\
\hline No activation & .49 & .20 & 22 \\
\hline
\end{tabular}

With questions that were not directly related to the particular idea question, the following effects were found: for students who were not very familiar with the concepts from the texts, the no activation condition resulted in higher scores on the posttests while the conditions contact and no activation led to comparable performance scores on the retention test; for "highly familiar" students, the no activation condition led to higher scores both on the posttests and on the retention test (see Figure 2).

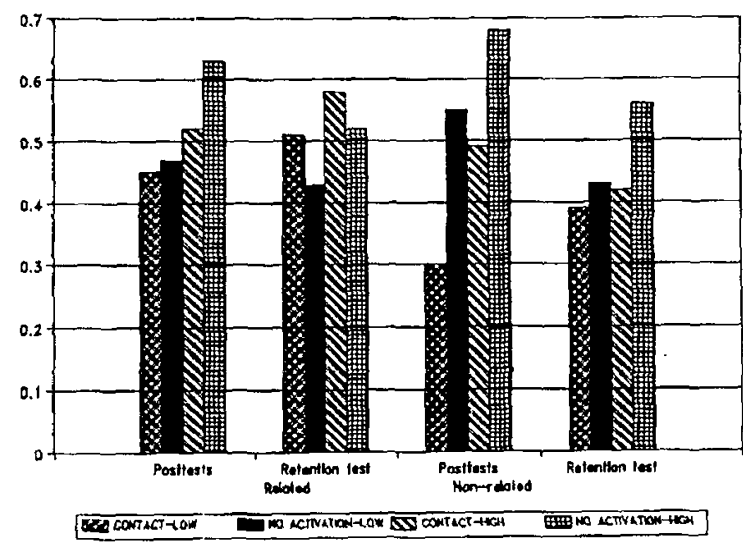

Figure 2. Mean scores for the instructional conditions contact and no activation (both for the High familiarity group and the Low familiarity group) with performance test questions that were directly related to the particular idea question and with questions that were not directly related (on the posttests and on the retention test)

The SLS data were analyzed by means of a repeated measurement ANOVA with two between-subjects factors (Instruction and Familiarity) and one within-subjects factor (SLS-scale). Because the data of 2 Ss were missing, the analysis was performed based on the data of 84 Ss.

This analysis revealed a significant main effect of the factor Instruction $(F(3,76)=3.65$, $p<.05)$ : significant differences were found between the conditions contact and no activation $(t=2.48, \mathrm{p}<.01)$ and new idea and no activation $(t=2.78, p<.01)$. Overall, Ss from the condi- 
tions contact and new idea had higher scores on the three parts of the SLS than Ss from the condition no activation (see Table 6 ).

\section{Table 5}

Mean scores, standard deviations and $N$ of Ss per cell for the eight Instruction X Familiarity groups with the performance test questions that were directly related to the particular idea question and with the questions that were not directly related (on the posttests and on the retention test)

\begin{tabular}{|c|c|c|c|c|c|}
\hline \multirow[b]{2}{*}{ Instruction conditions } & \multicolumn{2}{|c|}{ Related questions } & \multicolumn{3}{|c|}{ Non-related questions } \\
\hline & $M$ & $S D$ & $M$ & $S D$ & $N$ \\
\hline \multicolumn{6}{|l|}{ Posttests } \\
\hline \multicolumn{6}{|c|}{ Low familiarity } \\
\hline Contact & .45 & .07 & .30 & .07 & 7 \\
\hline New idea & .51 & .13 & .56 & .20 & 7 \\
\hline Old idea & .43 & .12 & .45 & .18 & 16 \\
\hline No activation & .47 & .16 & .55 & .18 & 11 \\
\hline \multicolumn{6}{|c|}{ High familiarity } \\
\hline Contact & .52 & .19 & .49 & .19 & 12 \\
\hline New idea & .53 & .19 & .49 & .22 & 13 \\
\hline Old idea & .55 & .10 & .49 & .15 & 5 \\
\hline No activation & .63 & .21 & .68 & .19 & 11 \\
\hline \multicolumn{6}{|c|}{ Retention test } \\
\hline \multicolumn{6}{|c|}{ Low familiarity } \\
\hline Contact & .51 & .13 & .39 & .11 & 7 \\
\hline New idea & .52 & .16 & .48 & .21 & 7 \\
\hline Old idea & .46 & .13 & .40 & .11 & 16 \\
\hline No activation & .43 & .16 & .43 & .20 & 11 \\
\hline \multicolumn{6}{|c|}{ High familiarity } \\
\hline Contact & .58 & .18 & .42 & .15 & 12 \\
\hline New idea & .51 & .14 & .38 & .20 & 13 \\
\hline Old idea & .46 & .15 & .33 & .105 & \\
\hline No activation & .52 & .24 & .56 & .23 & 11 \\
\hline
\end{tabular}

Table 6

Mean scores, standard deviations and $N$ of Ss per cell for the four Instruction conditions on the three parts of the SLS

\begin{tabular}{lccccccr}
\hline & \multicolumn{2}{c}{ Part I } & \multicolumn{2}{c}{ Part II } & \multicolumn{3}{c}{ Part III } \\
Instruction conditions & $M$ & $S D$ & $M$ & $S D$ & $M$ & $S D$ & $N$ \\
\hline Contact & .58 & .16 & .56 & .15 & .32 & .19 & 20 \\
New idea & .52 & .16 & .58 & .10 & .35 & .16 & 21 \\
Old idea & .51 & .13 & .50 & .13 & .29 & .14 & 21 \\
No activation & .47 & .15 & .47 & .15 & .29 & .16 & 22 \\
\hline
\end{tabular}


The main effect of the factor Familiarity $(F(1,76)=2.15, p=.15)$ and the interaction effect between Instruction and Familiarity $(F(3,76)=1.68, p=.18)$ were not significant. Moreover, the interaction effects involving the within-subjects factor SLS-scale turned out not to be significant.

\section{Conclusions and Discussion}

As mentioned in the section Introduction, the contact strategy was based on a theoretical framework concerning knowledge restructuring (see also Ali, 1990): taking into account the cognitive and instructional conditions formulated by Nussbaum and Novick (1982), Strike and Posner (1985), Prawat (1989) and other researchers in the field of conceptual change, this framework was converted into an activation model consisting of five steps aimed at conceptual change. Following Ali (1990, p. 143), we hypothesized that all the instructional steps from the activation model would contribute to the effectiveness of the strategy. Moreover, we assumed that the effectiveness of the strategy would depend on the degree of familiarity with the central concepts from the learning tasks (see Introduction section). Therefore, we hypothesized that the complete contact strategy would be the most effective variant for "highly familiar" students while students who are not very familiar with the concepts to be treated, would profit more from one of the dismantled variants.

With respect to the quality of the final conceptions of the students, these hypotheses could be accepted. Overall, the quality of the final conceptions of the students from the condition old idea was lower than the quality of the final ideas of the students from the conditions contact and new idea. If students were not very familiar with the central concepts from the training texts, the quality of the final ideas of the students from the conditions contact and new idea was comparable. However, if students were very familiar with these concepts, the quality of the final ideas of the students from the contact condition was higher than the quality of the final ideas of the students from the new idea condition. So, the various instructional treatments differentially affected students, depending upon their familiarity with the subject matter (see also Tobias, 1976).

For both groups of students, the condition old idea (in which students only had to perform the first step "searching for own preconceptions") led to final conceptions of the lowest quality. Apparently, students need more help to construct better conceptions. If students are not very familiar with the central concepts from the learning tasks, the additional support of the instructional steps "comparing and contrasting the preconceptions with the new information" and "formulating new conceptions" (as represented by the new idea strategy) seems to be sufficient (see also Prawat, 1989). Probably, students who are not very familiar with the concepts to be treated, do not need the guidance of the other two instructional steps because they do not hold many (mis)conceptions in advance because of a lack of former learning experiences involving these concepts (see also Johnson \& Kieras, 1983): as a consequence, they seem to be mainly involved in knowledge construction processes aimed at constructing new conceptions (as opposed to knowledge restructuring - changing existing conceptions - which seems to be more difficult to achieve - see also Eylon \& Linn, 1988).

For students who are very familiar with the concepts from the material to be learned, however, the additional support of the steps "applying the new conceptions" and "evaluating the new conceptions" does lead to conceptions of a higher quality. This result is in line with one of the conclusions drawn by Ali (1990): she reported that especially students who already were very familiar with the central concepts from the training texts profited from the contact strategy. At this point, it should be noted again that a high degree of familiarity as reported by a student indicates that he/she has often heard, read or seen something about the concepts to be dealt with in the learning material, probably because he/she is rather interested in this particular domain (see also Tobias, 1994). In other words, these students have had more learning experiences involving these concepts. As a result of these learning experiences, they appear to hold many elaborated preconceptions (both correct conceptions and incomplete/incorrect con- 
ceptions) that are quite resistant to change (see also Eylon \& Linn, 1988). This would explain why they need more instructional guidance with processes of knowledge reconstruction (see also Dochy, 1992). These students can use their own preconceptions as starting-point for knowledge restructuring. Because their preconceptions are integrated in a conceptual network, they must be activated to actually test and evaluate their conceptions. For them, being activated to contrast their preconceptions with the learning material is not sufficient. They need to experience whether their own ideas are valid or not. Only when they conclude that their ideas do not enable them to solve problems, they feel the need to change their conceptions (see also Strike \& Posner, 1985).

With respect to the training effects on the learning results of the students, we assumed that the effects of the contact strategy would depend on the degree of resemblance between the idea questions that were used to activate the preconceptions and the performance test questions. Following the selective-attention hypothesis (Pichert \& Anderson, 1977; Anderson \& Pichert, 1978; Goetz, Schallert, Reynolds, \& Radin, 1983; Machiels-Bongaerts, 1993), we hypothesized that the complete contact strategy would lead to the highest learning performance scores on directly related test questions and to the lowest scores on questions that were not directly related to the activated knowledge (as opposed to the no activation condition). Moreover, we hypothesized that the complete contact strategy would result in better maintenance of the acquired knowledge than the other three instructional conditions.

Our study revealed that the relation between instructional condition and type of performance test question was indeed dependent on the degree of familiarity of the students and on the moment of testing. With questions that were directly related to the particular idea question, the contact strategy resulted in better learning performance than the no activation condition (in the longer terra - as measured by the retention test). This effect was found both for "highly familiar" students and for students who were not very familiar with the concepts from the texts. These higher learning performance scores with related questions are in concordance with the selective-attention hypothesis: apparently, students who study texts guided by the contact strategy, mainly focus on the relations between the central concepts from the texts (as represented by the "exposing events" - see also Nussbaum \& Novick, 1982). The information corresponding with the activated knowledge is processed in depth, resulting in better recall of that information.

With questions that were not directly related to the particular idea question, the no activation condition resulted in higher scores than the contact strategy. This effect faded in the longer term for students who were not very familiar with the concepts from the texts. These results are also in line with the selective-attention hypothesis: because students from the contact condition focus more on the relations between the central concepts, their attention is less directed at the other information from the texts. The learning activities corresponding with the various steps of the contact strategy demand a considerable amount of information processing capacity: students from the contact condition reported a higher frequency of usage of activities that can be performed to construct a correct conception (the contact activities) than students from the condition no activation (see the results concerning part II of the SLS). As a consequence, these students lack the capacity to study the peripheral information from the text in depth (and perhaps also the motivation to study these parts that might be seen as less relevant). Students from the condition no activation, however, can concentrate on the text as a whole. Probably, this effect is even stronger for "highly familiar" students because they seem to be mainly involved in knowledge restructuring (as opposed to knowledge construction processes).

For students from the contact condition, the learning performance scores on the posttests and on the retention test were comparable while for students from the other three instructional conditions, there was a decrease of the performance scores. Students working with these dismantled variants, seem to construct a "corpus alienum" for the new knowledge that can not serve as a solid base for retrieval in the long term. On the other hand, students who are supported by the complete contact strategy while studying texts, appear to construct more valid and integrated conceptions with more adequate retrieval paths, resulting in better maintenance of the acquired knowledge (see also Schmidt, 1982). 
Based on these findings, one can argue that the contact strategy is effective as instructional strategy aimed at conceptual change (especially for "highly familiar" students) because students construct correct conceptions that represent the relations between the central concepts from the learning task (students from the contact condition also identified the highest number of learning activities that can be performed to construct a correct conception - see the results concerning part I of the SLS) and because they achieve better learning results with related performance test questions ("near transfer" - see Simons \& Verschaffel, 1992). In other words, the underlying activation model (see also Ali, 1990) that was based on the cognitive and instructional conditions formulated by Nussbaum and Novick (1982), Strike and Posner (1985), Prawat (1989) and others, turned out to be valid and useful. Because of the rather small sample size in our study, however, we would like to stress the need for additional research on the effectiveness of the activation model. Additional research is also needed concerning the negative side-effect that was found in our study: students seem to concentrate on parts of the learning task and not on the whole text which results in lower performance scores with test questions that are not directly related to the central concepts of the texts ("far transfer" - see Simons \& Verschaffel, 1992).

Nevertheless, we would like to formulate some implications for the design of process-oriented instructional strategies airned at activation of prior knowledge. On the one hand, such instructional strategies should support the process of conceptual change and, on the other hand, they should offer a solution for the problem of selective attention. With respect to the contact strategy, the efficiency and flexibility of the strategy could be increased by stressing the relevance of the strategy, providing optional "on-line" support aimed at clarifying the steps of the strategy (students from the contact condition did not give very accurate descriptions why it is important to perform the various steps and how these steps can be performed - see the results concerning part III of the SLS), stressing the need to do the corresponding learning activities in a profound way (e.g., by using work-sheets), optimizing the lay-out of the training program, activating the student's preconceptions in various (textual, visual) ways ("multiple bridging"; see also Spiro, Feltovich, Jacobson, \& Coulson, 1991), making the strategy as sensitive as possible to the student's progress, etc. The student's attention could be drawn to the learning task as a whole and not just to the relations between the central concepts by stressing the goal of the training (comprehension of the whole text), accentuating all important concepts from the learning material, optimizing the scrolling options, reducing the amount of information concerning the steps of the strategy the student is obliged to read, etc. In our view, instructional designers should both strive for increased efficiency and flexibility of the strategy and try to draw the student's attention to the learning task as a whole and not just to the relations between the central concepts. Therefore, in a follow-up study, the effectiveness of a revised version of the contact strategy based on these prescriptions will be examined.

For the moment, the contact strategy seems promising as process-oriented instructional strategy aimed at activation of preconceptions. This conclusion could also be relevant for educational practice. Instructional strategies typified by continuous activation of conceptions can enable individual students to use their own conceptions as starting-points for knowledge restructuring. Moreover, these strategies can activate them to employ learning activities aimed at conceptual change. Therefore, it is recommended, following Dochy (1992, p. 188), that refined prior knowledge tests are incorporated as a recurrent feature in courses and curricula and that the feedback function of support provisions is extended by making use of the information obtained by prior knowledge tests. In our view, specific support to individual knowledge (re)construction processes is necessary: the present study shows that smanytudents need the support of an instructional strategy to activate their preconceptions and to construct correct conceptions.

\section{Notes}

1 When a significant effect involving the factor Instruction was found, post-hoc analyses were carried out in which the various Instruction conditions were contrasted in pairs. With these post-hoc analyses, a critical significance level of 0.01 was used (Winer, 197!). 


\section{References}

Alexander, P. A., Pate, E. P., Kulikowich, J. M., Farrell, D. M., \& Wright, N. L. (1989). Domain-specific and strategic knowledge: Effects of training on students of diftering ages or competence levels. Learning and Individual Differences, $1,283-325$.

Ali, K. S. (1990). Instructiestrategieën voor het activeren van preconcepties [Instructional strategies to activate preconceptions]. Doctoral dissertation. Helmond: Wibro.

Anderson, R. C., \& Pichert, J. W. (1978). Recall of previously unrecallable information following a shift in perspective. Journal of Verbal Leaming and Verbal Behavior; 17, 1-12.

Ausubel, D. P. (1958). Educational Psychology: A cognitive view'. New York: Holt, Rinehart \& Winston.

Biemans, H. J. A. (1989). Effecten van een metacognitief trainingsprogramma [Effects of a metacognitive training program]. Tijdschrift voor Onderwijstesearch, 14, 286-296.

Biemans, H. J. A., \& Simons, P. R. J. (1992). Learning to use a word processor with concurrent computer-assisted instruction. Learning and linstruction, 2,321-338.

Brown, J. S., Coll ns, A., \& Duguid, P. (1989). Situated cognition and the culture of learning, Educational Researcher, $18,32-42$.

De Jong, F. P. C. M., \& Simons, P. R. J. (1990), Cognitive and metacognitive processes of self-regulated learning. In J. M. Pieters, P. R. J. Simons, \& L. de Leeuw (Eds.), Research on computer-based instruction (pp. 81-100). Lisse: Swets \& Zeitlinger.

Dochy, F. J. R. C. (1988). Het effect van de "prior knowledge state" op het leren: Theorieën en onderzoek [The effect of the "pricr knowledge state" on learning: Theories en research]. Heerlen: Open University.

Dochy, F. J. R. C. (1992). Assessment of prior knowledge as a determinant for future learning. Doctoral dissertation. Heerlen: Open University.

Eylon, B., \& Linn, M. C. (1988). Learning and instruction: An examination of four research perspectives in science education. Review of Educational Research, 58, 251-301.

Glaser, R. (1991). The maturing of the relationship between the science of learning and cognition and educational practice. Learning and Instruction, 1, 129-144.

Goetz, E. T., Scrallert, D. L., Reynolds, R. E., \& Radin, D. I. (1983). Reading in perspective: What real cops and pretend burglars look for in a story. Journal of Educational Psychology, 75, 500-510.

Hewson, P. W., \& Hewson, M. G. A. (1984). The role of conceptual conflict in conceptual change and the design of science instruction. Instructional Science, 13, 1-13.

Johnson, W., \& Kieras, D. (1983). Representation-saving effects of prior knowledge in memory for simple technical prose. Menory and Cognition. 11, 456-466.

Körkel, J. (1987). Die Entwicklung von Gedächmis - und Metagedächtnisleistungen in Abhängigkeit von bereichsspezifischen Vorkenntnissen. Frankfurt: Peter Lang.

Machiels-Bongaerts, M. (1993). Mobilizing prior knowledge in text processing: The selective-attention hypothesis versus the crgnitive set-poim hypothesis. Doctoral disserlation. Maastricht: University of Maastricht.

Nussbaum, J., \&: Novick, S. (1982). Alternative frameworks, conceptual conflict and accommodation: Towards a principled teaching strategy. Instructional Science. $1 /, 183-200$.

Pfund, H., \& Duit, R. (1991). Bibliography: Students' alternative fiameworks and science education (3rd edition). Kiel: I.P.N.

Pichert, J. W., \&z Anderson, R. C. (1977). Taking different perspectives on a story. Joumal of Educational Psychology, $69,309-215$. 
Prawat, R. S. (1989). Promoting access to knowledge, strategy and disposition in students: A research synthesis. Revicw of Educational Research, 59, 1-41.

Salomon, G. (1989). Technology for the mind: Partner and nourisher. In P. Span \& E. de Corte (Eds.), Onderwijsleerprocessen [Teaching-learning processes] (pp. 1-12). Lisse: Swets \& Zeitlinger.

Schmidt, H. G. (1982). Activatic van voorkemis, intrinsieke motivatie en de verwerking van tekst [Activation of prior knowledge, intrinsic motivation and text processing]. Apeldoorn: Van Walraven.

Schmidt, H. G. (1984). Activatie van voorkennis en tekstverwerking [Activation of prior knowledge and text processing]. Tijdschrift voor de Psychologie, 39, 335-347.

Schmidt, H. G. (1988). Opsporen van misconcepties bij middelbare scholieren [Tracing misconceptions with high school students]. Tijdschrift voor Onderwijsresearch, 13, 129-140.

Siegler, R. S. (1983). Five generalizations about cognitive development. American Psychologist, 38, 263-277.

Simons, P. R. J., \& Verschaffel, L. (1992). Transfer: Onderzoek en onderwijs [Transfer: Research and education]. Tijdschrift voor Onderwijsresearch, 17, 3-16.

Spiro, R. J., Feltovich, P. J., Jacobson, M. J., \& Coulson, R. L. (1991). Cognitive flexibility, constructivism, and hypertext: Random access instruction for advanced knowledge acquisition in ill-structured domains. Educational Technology, 5, 24-33.

Strike, K. A., \& Posner, G. J. (1985). A conceptual change view of learning and understanding. In L. H. T. West \& A. L. Pines (Eds.), Cognitive structure and conceptual change (pp. 211-231). Orlando: Academic Press.

Tergan, S. O., \& Oestermeier, U. (1993a, August). GELERIAT: A multifinctional generative learning environmem for promoting conceptual change in elementary mechanics. Poster presented at the Al-ED 93 World Conference, Edinburgh, Great Britain.

Tergan, S. O., \& Oestermeier, U. (1993b, September). Designing learning environments for conceptual change: A cognitive approach. Paper presented at the Fitth Conference of the European Association for Research on Learning and Instruction, Aix-en-Provence, France.

Tabachnik, B. G., \& Fidell, L. S. (1983). Using multivariate statistics. New York: Harper \& Row.

Tobias, S. (1976). Achievement treatment interactions. Review of Educational Research, 45, 89-125.

Tobias, S. (1994). Interest, prior knowledge, and learning. Review of Educational Research, 64, 37-54.

Vermunt, J. D. H. M. (1992). Leerstijlen en sturen van leerprocessen in het hoger onderwijs: Naar procesgerichte instructie in zelfstandig denken [Learning styles and regulation of learning in higher education: Towards process-oriented instruction in autonomous thinkingl. Doctoral dissertation. Lisse: Swets \& Zeitlinger.

Vonk, W. (1986, September). Readers" perspective and selective processing. Paper presented at the Conference "Les textes et leur traitement", Poitiers, France.

Voss, J. F. (1987). Learning and transfer in subject-matter learning: A problem-solving model. International Journal of Edicational Research, 11, 607-622.

Weinert, F. E. (1989). The impact of schooling on cognitive development: One hypothetical assumption, some empirical results, and many theoretical implications. EARLI new's, 8, 3-7.

Weinert, F. E., \& Helmke, A. (1993, September). Learning from wise mother nature or big brother instructor: The wrong alternative for cognitive developmem. Paper presented at the Fifth Conference of the European Association tor Research on Learning and instruction, Aix-en-Provence, France.

Winer, B. J. (1971). Statistical principles in experimental design (2nd edition). New York: McGraw-Hill. 
Key words: Computer-assisted instruction, Conceptual change, Prior knowledge, Process-oriented instruction, Reading comprehension.

Harm J. A. Biemans. Department of Agricultural Education, University of Wageningen, P.O. Box 8130, 6700 EW Wageningen, The Netherlands.

Current theme of iesearch:

Conceptual change. Computer-assisted instruction. Learning to learn Agricultural Education.

Most relevant putlications in the field of Psychology of Education:

Biemans, H. J. A., \& Simons, P. R. J. (1991). Effekte der Einbettung von metakognitiven Fragen und Regulationshinweisen in ein computerunterstütztes Lernprogramm zur Textverarbeitung auf die Lernleistungen. Empirische Pädagogik. 5, 125-141.

Biemans, H. J. A., \& Simons, P. R. J. (1992). Learning to use a word processor with concurrent computer-assisted instruction. Learning and Instruction, 2, 321-338.

Biemans, H. J. A. (1994). Activation of preconceptions as part of process-oriented instruction. In F. P. C. M. de Jong \& B. H. A. M. van Hout Wolters (Eds.), Process-oriented instruction and learning from text (pp. 27-36). Amsterdarn: VU University Press.

P. Robert-Jan Simons. Department of Educational Sciences, University of Nijmegen, P.O. Box 9104, 6500 HE Nijmegen, The Netherlands.

Current theme of research:

Learning to learri. Professional training.

Most relevant pliblications in the field of Psychology of Education:

Simons, P. R. J., \& Jong, F. P. C. M. de (1992). Self-regulation and computer-aided instruction. Applied Psychology: An Internaticnal Review, 41, 333-346.

Teurlings, C. J., \& Simons, P. R. J. (1992). Effects of the use of Leittexts in learning to use word processors. Journal of European Industrial Training, 16, 29-38.

Simons, P. R. J. (1993). Constructive learning: The role of the learner. In T. M. Duffy, J. Lowyck \& D. H. Jonassen (Eds.), Designing environments for constructive learning (pp. 291-313). Berlin: Springer.

Simons, P. R. J. (1994). How natural, situated and skill-oriented is anchored instruction. In B. P. M. Creemers \& G. J. Reezigt (Eds.), New directions in educational research (pp. 63-70). Groningen: 1.C.O. 